\title{
Relationship between energy availability, energy conservation and cognitive restraint with performance measures in male endurance athletes
}

\author{
Iva Jurov ${ }^{1 *}$ (D) Nicola Keay ${ }^{2}$, Vedran Hadžić ${ }^{1}$, Darjan Spudić ${ }^{1}$ and Samo Rauter ${ }^{1}$
}

\begin{abstract}
Background: Low energy availability in male athletes has gained a lot of attention in recent years, but direct evidence of its effects on health and performance is lacking. The aim of this research was to objectively measure energy availability (EA) in healthy male endurance athletes without pre-existing relative energy deficiency signs during pre-race season.

Methods: Twelve trained endurance athletes (performance level 3, 4, and 5) participated in the cross-sectional controlled laboratory study. Fat-free mass, exercise energy expenditure, and energy intake were measured to calculate EA. Resting energy expenditure was measured and estimated to assess energy conservation. Three specific performance tests were used to assess endurance, agility, and explosive strength performance. For psychological evaluation, the Three Factor Eating Questionnaire and a short Well-being questionnaire were completed.

Results: Mean EA was $29.5 \mathrm{kcal} / \mathrm{kg}$ FFM/day. The majority (66.6\%) had EA under the threshold for low EA in females. Critical cognitive restraint $(\geq 13)$ was reported by $75 \%$ of participants. There were no differences in performance, blood values, or psychological evaluation when subjects were divided into two groups divided by $\mathrm{EA}=30 \mathrm{kcal} / \mathrm{kg} \mathrm{FFM} /$ day. Cognitive restraint was negatively associated with measured resting energy expenditure and energy conservation ( $r=-.578, p=.025$ and $r=-.549, p=.032$, respectively).

Conclusions: The mean EA measured in this study supports the theory that the threshold for low EA in endurance male athletes might be under the threshold for females. In addition, we confirmed cognitive restraint could be useful for early detection of energy conservation. The high cognitive restraint as measured in our sample stressed the need of eating behavior screening in endurance athletes in order to reduce risk of any disordered eating patterns.
\end{abstract}

Keywords: Energy availability, Performance, Endurance athletes, Relative energy deficiency, Cognitive restriction

\footnotetext{
* Correspondence: iva.jurov@gmail.com

${ }^{1}$ Faculty of Sport, University of Ljubljana, Gortanova 22, 1000 Ljubljana,

Slovenia

Full list of author information is available at the end of the article
}

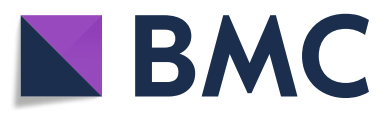

(c) The Author(s). 2021 Open Access This article is licensed under a Creative Commons Attribution 4.0 International License, which permits use, sharing, adaptation, distribution and reproduction in any medium or format, as long as you give appropriate credit to the original author(s) and the source, provide a link to the Creative Commons licence, and indicate if changes were made. The images or other third party material in this article are included in the article's Creative Commons licence, unless indicated otherwise in a credit line to the material. If material is not included in the article's Creative Commons licence and your intended use is not permitted by statutory regulation or exceeds the permitted use, you will need to obtain permission directly from the copyright holder. To view a copy of this licence, visit http://creativecommons.org/licenses/by/4.0/ The Creative Commons Public Domain Dedication waiver (http://creativecommons.org/publicdomain/zero/1.0/) applies to the data made available in this article, unless otherwise stated in a credit line to the data. 


\section{Background}

Endurance athletes are at risk for development of a syndrome called relative energy deficiency in sport (RED-S) [1]. Low energy availability (LEA) is the underlying cause for RED-S [2]. Estimated prevalence of LEA is high [3] but methodology for assessment is not universal and often based on questionnaires and subjective estimation. The threshold for LEA is known in female athletes $(30 \mathrm{kcal} / \mathrm{kg}$ fat-free mass(FFM)/day) [4], but the equivalent in men is yet to be confirmed. While diagnosing athletes with obvious RED-S signs and symptoms is relatively straightforward, detecting LEA before detrimental health issues arise presents a greater challenge. It is also unclear how and when LEA affects performance. Clearly, performance is of the greatest interest to athletes and their coaches. Unfortunately, there is currently little research directly observing LEA's association with performance. Our current knowledge on performance effects is mostly theoretical [2, 5]. Objective methodology for measuring EA is the only way to discover the threshold of LEA in men. After a threshold (or a range for LEA) is confirmed, we will then be in a better position to elucidate the effects on performance more readily. There is speculation that performance effects could arise before clinical signs of poor well-being. This is why measuring EA status in apparently healthy athletes could provide insight into the association of EA with performance.

In times of energy deprivation, energy is spared at the cost of growth and reproduction [6]. Metabolic changes in the body can result in energy conservation in order to ensure homeostasis. There are more mechanisms underlying energy conservation [7], which is detected by ratio of measured resting energy expenditure (mREE) and predicted resting energy expenditure (pREE) - the mREE/pREE ratio. It was previously reported that energy conservation could be a useful marker for detecting LEA. In female athletes $\mathrm{mREE} / \mathrm{pREE}$ ratio $<0.9$ was associated with relative energy deficiency $[8,9]$ and with poor aerobic performance in competitive female cyclists [10], but there were no reported cutoff values in men.

The primary endpoint of our study was to objectively measure energy availability (EA) in trained male endurance athletes without pre-existing RED-S signs during pre-race season and to evaluate and quantify possible relationships between measured EA and mREE/pREE, specific blood marker and performance parameters. Our secondary endpoint was analysis of the relationship between cognitive restraint and EA, as there is evidence in the literature suggesting that psychological questionnaires might be a better tool for RED-S screening than endocrine markers [11].

\section{Methods}

\section{Study design}

This was a cross-sectional controlled laboratory study. With unchanged living and training conditions, subjects reported energy intake (EI) by completing dietary diaries for 7 consecutive days [12] (Fig. 1). During this period, exercise energy expenditure (EEE) was monitored during all training units. After 7 days, blood samples were drawn and after 1 day of rest (on day 9), body composition was assessed and REE was measured, followed by three performance tests for determining basal performance. At the end of the study, participants completed psychological questionnaires.

\section{Participants}

Eighteen $(N=18)$ males were invited to participate in this research. Inclusion criteria for participation in the study are presented in Table 1 and flowchart of enrollment in Fig. 2.

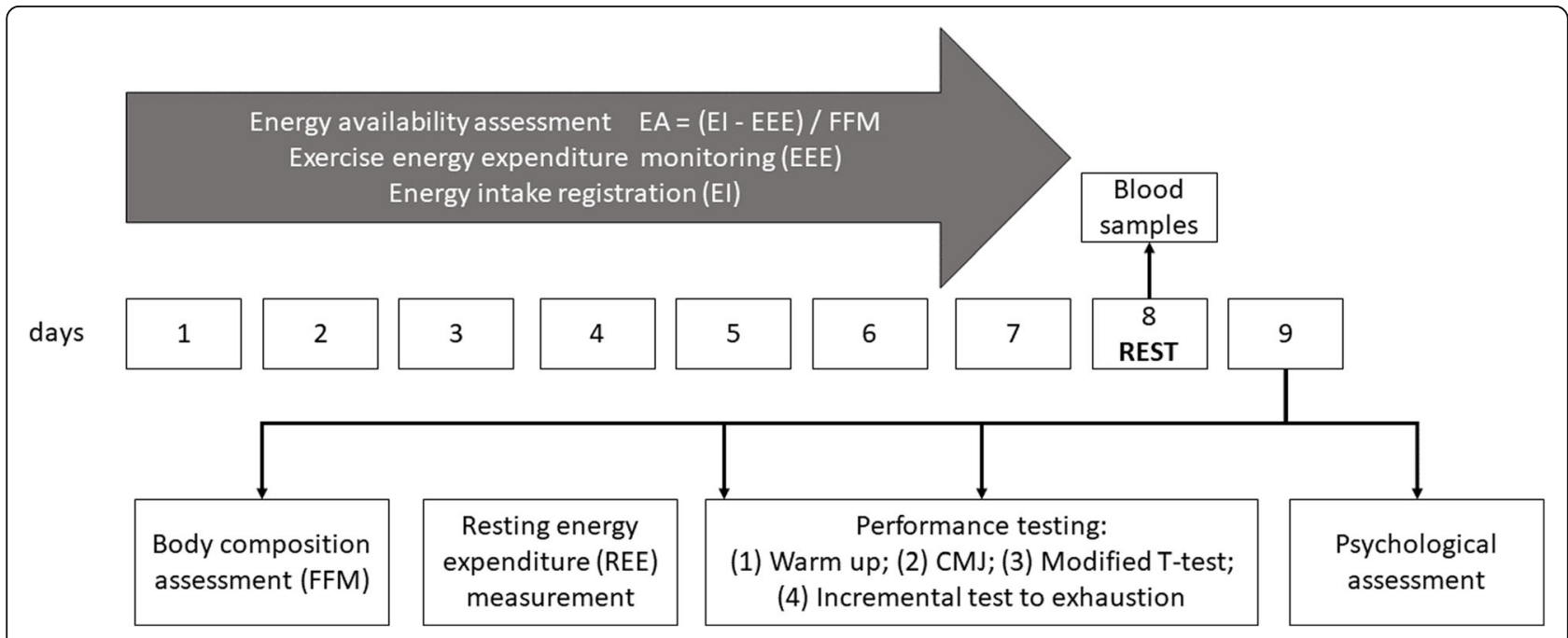

Fig. 1 The timeline of all procedures and measurements 
Table 1 Inclusion criteria for participants

\begin{tabular}{|c|c|}
\hline Sex & Male \\
\hline Age & $18-35$ years \\
\hline Performance level & Well trained; with VO2max 55-64.9 ml/kg/min; performance level 3 or more [13] \\
\hline BMI & 1. BMI $19-25 \mathrm{~kg} / \mathrm{m}^{2}$; in normal range for adult males) \\
\hline Body Fat Percentage & 2. $5-20 \%$ \\
\hline Health status & $\begin{array}{l}\text { 1. No acute disease or chronic disease in relapse (allowing only for chronic diseases that are stable and not affecting } \\
\text { performance) } \\
\text { 2. At the time of procedures be free of injuries and no injuries in previous three months that could affect performance }\end{array}$ \\
\hline \multirow[t]{4}{*}{ Additional criteria } & 3. Stable body mass for the last 12 months \\
\hline & 4. Not undertaking any specific diet regime \\
\hline & 5. At the time of procedures will refrain from alcohol consumption and any drug or other substance use \\
\hline & $\begin{array}{l}\text { 6. Complete all procedures and report any factors that could influence changes in blood values or performance (lack } \\
\text { of motivation due to psychological factors, factors in between measurements that could influence results etc.) }\end{array}$ \\
\hline
\end{tabular}

All participants needed to sign an informed consent before commencing all protocols for allowing data to be gathered and analyzed anonymously. This research complied with the declaration of Helsinki. National medical ethical approval was acquired before the start of the study (No. 0120-202/2020/5).

\section{Subject involvement}

Subjects were invited to participate in the study through national cycling and triathlon organizations, professional cycling team's coaches. The information was also disseminated through faculty's laboratory, where national best endurance athletes regularly perform various testings.

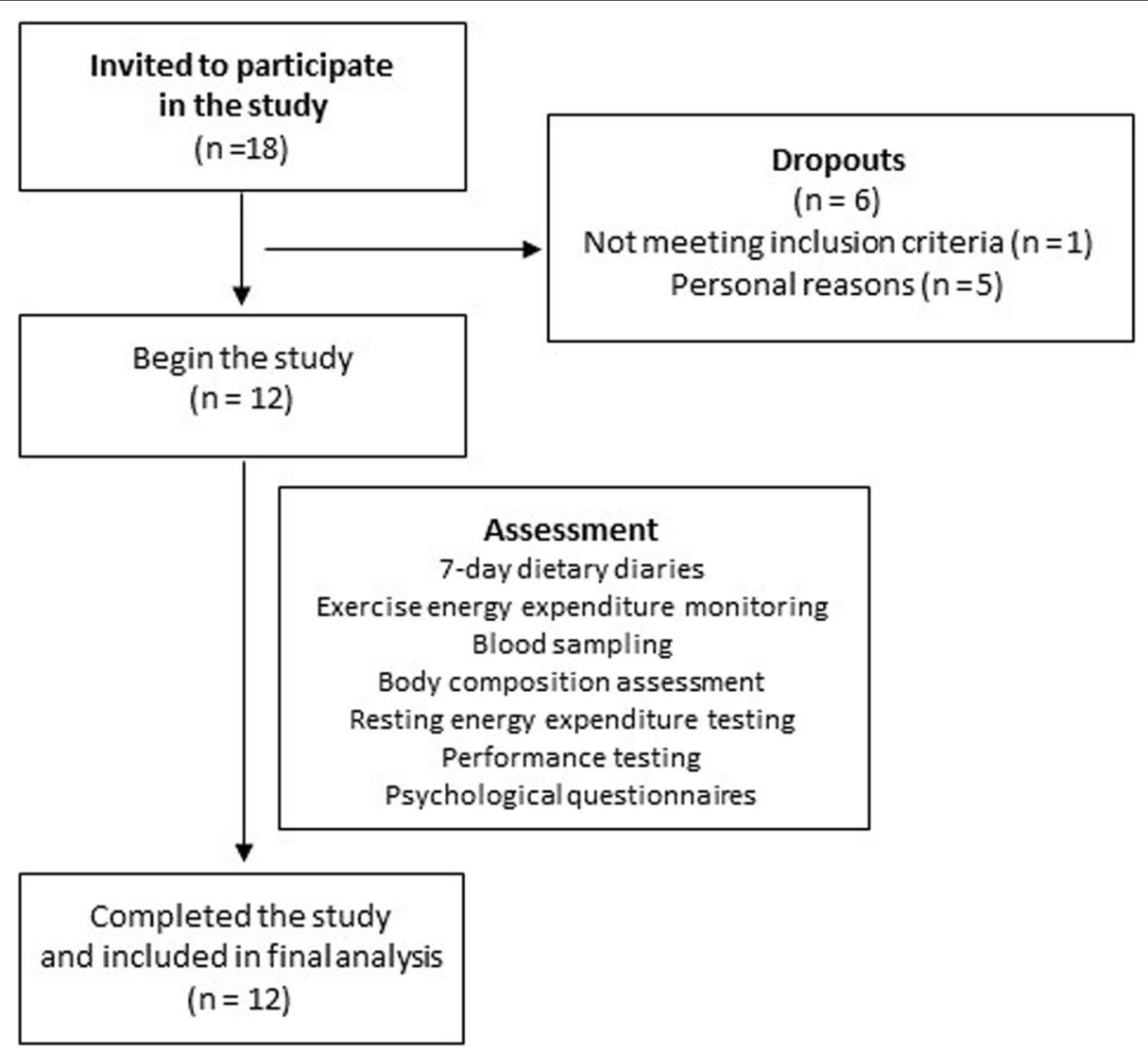

Fig. 2 Flowchart of participant enrollment in the study 
Subjects were informed of all procedures and were selected based on inclusion criteria, high motivation and compliance.

\section{Procedures \\ Energy availability calculation}

All procedures were carried during a 9-day period (Fig. 1). Participant EI was measured by completing dietary diaries for 7 consecutive days [12]. All participants received detailed information on how to complete the diary and how to weigh food or measure its quantity with the help of cups and other measuring tools. They were asked to provide photographic evidence of all food and liquid ingested in that time. EI data was analyzed with Foodworks 9 Professional Edition (version 9.0.3973, Xyrix Software, Australia). During this same period EEE was estimated from heart rate using wearable heart rate monitors during all exercise sessions (Polar V800, Polar Electro, Kempele, Finland). EA was calculated as EA = (EI-EEE)/FFM.

\section{Performance testing}

To test performance, three different tests were chosen to assess explosive power of lower extremity (Countermovement jump), motor task execution time (agility t-test) and maximal aerobic capacity (incremental aerobic endurance test). The details of warm-up protocol and tests can be found in the Additional file 1.

First, CMJ test was performed using a bilateral force plate system (Type 9260AA, Kistler Instrumente AG, Winterthur, Switzerland) with Kistler MARS software (S2P Ltd., Ljubljana, Slovenia) to acquire ground reaction force. Each subject has performed three to five maximal counter movement jumps before the testing.

Second, to asses motor task execution time, validated modified agility t-test was used, as described by Haj-Sassi, et al. (2011). The time of best repetition (seconds) were used in further analysis.

After $1 \mathrm{~h}$ of rest, endurance was measured with the incremental test to exhaustion. Heart rate, ventilatory, and gas data were collected during the incremental test with metabolic cart (V2 mask (Hans Rudolph, USA), K5 (Cosmed, Albano Laziale, Rome, Italy) with Quark 8.1. PC software support) on a cycle ergometer (Cyclus 2, Leipzig, Germany).

\section{Blood samples}

On day 8 , venous blood samples were drawn in the morning at $9 \mathrm{am}$ in a fasted state to assess complete blood count, ferritin, serum iron (Fe), triiodothyronine (T3), thyroid stimulating hormone (TSH), morning testosterone, fasting insulin, insulin like growth factor 1 (IGF-1) and 9 am cortisol. Blood was collected using standard clinical procedures. Haemoglobin was analysed with Sysmex XN-550 (photometric detection, EDTA tubes), iron with Cobas c501 (colorimetric analysis, serum tubes), ZSH, T3, testosterone, cortisol and ferritin with Cobas e411 (electrochemiluminescence immunoassay, serum tubes). Serum insulin level was analyzed with a double antibody RIA (serum tubes) and for IGF-1 the RIA kit (serum tubes) was used.

\section{Body composition assessment}

Body composition was assessed using tetra polar eight point tactile bioelectrical impedance device InBody 720 (Biospace, Seul, South Korea) on day 9. Prior to body composition measurement, participants received instructions how to be adequately hydrated to enable precise measurement of FFM and body fat percentage that were used in further analysis.

\section{Resting energy expenditure assessment}

REE was measured with indirect calorimetry (V2 mask (Hans Rudolph, USA), K5 (Cosmed, Albano Laziale, Rome, Italy) with Quark 8.1. PC software support) based on the Weir equation [14, 15]. The measurement was performed in a thermoneutral environment, in silence, between 6.00 and $9.00 \mathrm{a} . \mathrm{m}$., after $12 \mathrm{~h}$ of fasting [16]. It lasted $30 \mathrm{~min}$ and the final $20 \mathrm{~min}$ were used for REE measurement [17]. During REE measurement, respiratory quotient was monitored since measures under 0.70 or above 1 suggest protocol violations or inaccurate gas measurement [17]. To obtain predicted REE (pREE), a Harris-Benedict equation was used [18]. The mREE/ pREE ratio was then calculated for further analysis.

\section{Psychological assessment}

The Three Factor Eating Questionnaire (TFEQ-R18) and Well-being questionnaire were used for psychological assessment $[19,20]$. TFEQ-R18 was used to detect early changes in eating behaviors and has three subscales including cognitive restraint, disinhibition and susceptibility to hunger, with higher scores indicating greater eating disturbances in participants. The subscale of interest was cognitive restraint. General well-being was assessed by a simple questionnaire as recommended by Hooper and Mackinnon (1995) including six subjective ratings (fatigue, sleep, stress, muscle soreness, mood and morning erections) on a 1-5 scale. The last item about morning erections was added to the original set as proposed by a study on professional rugby players [21] (Additional file 2).

\section{Data analysis}

All data were analyzed using the IBM SPSS Software for Windows (version 21, SPSS Inc., Armonk, New York, USA). Categorical variables are displayed as numbers and percentages, and numeric variables are presented as means and standard deviations. All numeric variables were first checked for normality of distribution with 

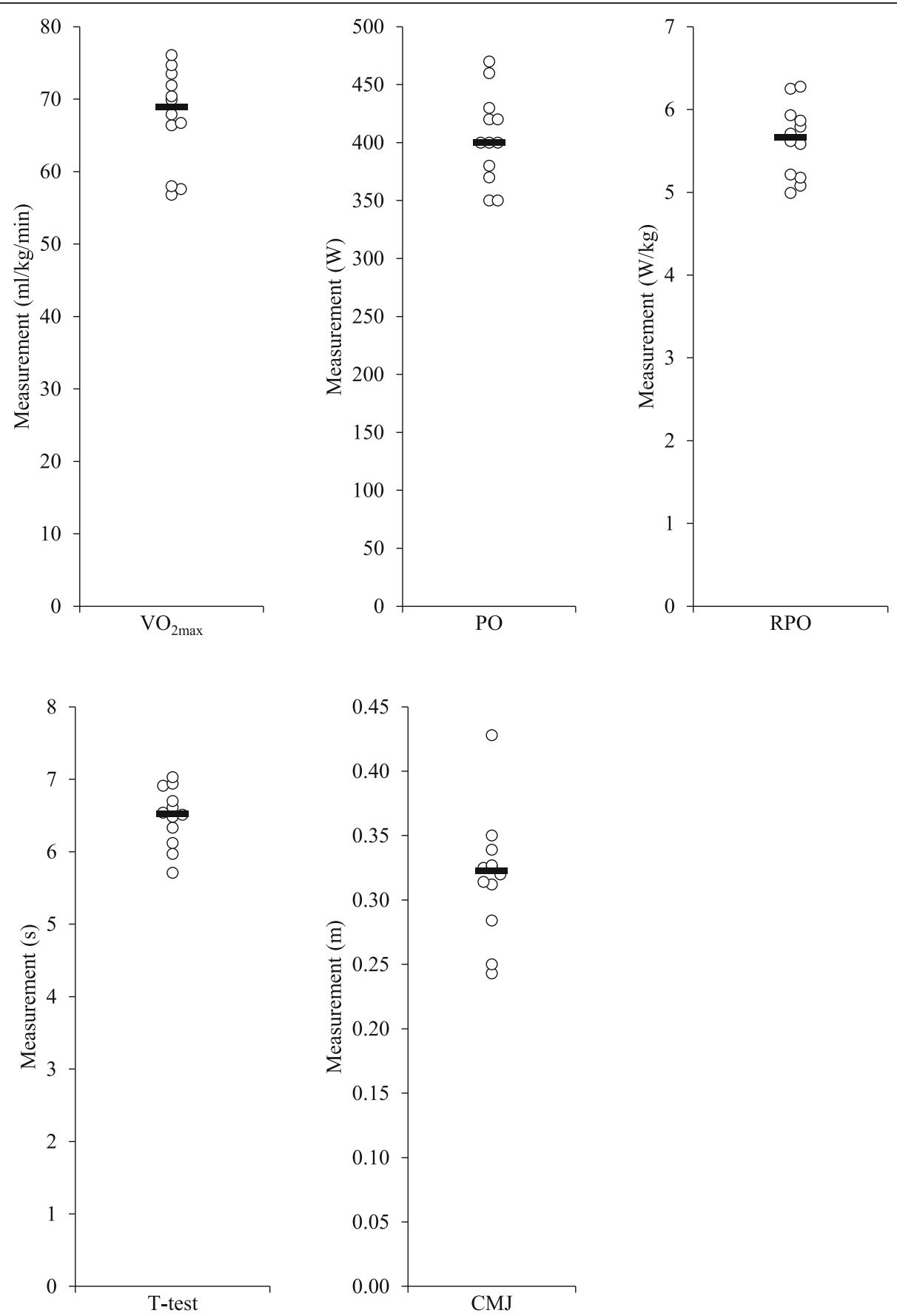

Fig. 3 Scatterplots of performance parameters (PO - peak power output, RPO - relative power output, $\mathrm{VO}_{2 \max }$ - maximal oxygen uptake, CMJ countermovement jump)

Shapiro-Wilk's test. Pearson's correlation coefficient was computed to assess the relationship between EA and obtained performance, laboratory, body composition and psychological parameters. Based on the EA value, the subjects were later divided into two subgroups (with $\mathrm{EA} \geq 30 \mathrm{kcal} / \mathrm{kg}$ FFM/day and with EA $<30 \mathrm{kcal} / \mathrm{kg}$ FFM/ day). The possible differences in performance, blood, anthropometric, body composition, and psychological parameters between those two groups were analyzed using the t-test for independent samples. The significance level was set at $p$-values $<0.05$ for all calculations.

\section{Results}

The means and standard deviations of all obtained parameters are presented in Table 2. 
Table 2 All obtained parameters in the study design

\begin{tabular}{|c|c|c|c|}
\hline & Parameters & Mean & Std. Dev. \\
\hline \multirow[t]{6}{*}{ Anthropometrics and body composition parameters } & Age (years) & 27.5 & 5.7 \\
\hline & Body height $(\mathrm{cm})$ & 179.8 & 4.4 \\
\hline & Body mass (kg) & 71.8 & 3.6 \\
\hline & Fat-free mass - FFM (kg) & 64.5 & 3.7 \\
\hline & \%FFM (\%) & $89.8 \%$ & $2.5 \%$ \\
\hline & Percentage body fat (\%) & $10.2 \%$ & $2.5 \%$ \\
\hline \multirow[t]{6}{*}{ Energy and metabolic parameters } & Energy intake (kcal/day) & 3078 & 520 \\
\hline & Exercise energy expenditure (kcal/day) & 1173 & 420 \\
\hline & mREE (kcal/day) & 1824 & 357 \\
\hline & pREE (kcal/day) & 1770 & 68 \\
\hline & mREE/pREE ratio & 1.03 & 0.21 \\
\hline & Energy availability (kcal/day/kg FFM) & 29.5 & 7.9 \\
\hline \multirow[t]{10}{*}{ Blood samples } & Haemoglobin (g/L) & 146.83 & 9.28 \\
\hline & S-Iron ( $\mu \mathrm{mol} / \mathrm{L})$ & 22.91 & 3.93 \\
\hline & S-TSH (mIU/L) & 2.37 & 0.67 \\
\hline & S-T3 (pmol/L) & 4.46 & 0.54 \\
\hline & S-Testosterone (nmol/L) & 17.74 & 3.53 \\
\hline & S-Cortisol (nmol/L) & 454.37 & 88.46 \\
\hline & S-Feritin $(\mu \mathrm{g} / \mathrm{L})$ & 129.43 & 99.03 \\
\hline & Insulin (mE/L) & 2.84 & 1.33 \\
\hline & IGF-1 ( $\mu \mathrm{g} / \mathrm{L})$ & 186.17 & 55.21 \\
\hline & IGF-1 SD & -0.19 & 0.81 \\
\hline \multirow[t]{9}{*}{ Performance parameters } & $\mathrm{VO}_{2 \max }(\mathrm{ml} / \mathrm{min} / \mathrm{kg})$ & 67.49 & 6.74 \\
\hline & $\mathrm{PO}(\mathrm{W})$ & 402.50 & 40.03 \\
\hline & $\mathrm{RPO}(\mathrm{W} / \mathrm{kg})$ & 5.60 & 0.47 \\
\hline & AT $(\mathrm{ml} / \mathrm{min} / \mathrm{kg})$ & 47.10 & 5.99 \\
\hline & $\mathrm{RC}(\mathrm{ml} / \mathrm{min} / \mathrm{kg})$ & 57.48 & 7.12 \\
\hline & {$[\mathrm{La}]_{\max }(\mathrm{mmol} / \mathrm{l})$} & 10.80 & 2.46 \\
\hline & {$[\mathrm{La}]_{5 \min }(\mathrm{mmol} / \mathrm{l})$} & 11.29 & 2.07 \\
\hline & Modified t-test (seconds) & 6.49 & 0.40 \\
\hline & Countermovement jump height (cm) & 32 & 5 \\
\hline \multirow[t]{3}{*}{ Psychological assessment } & Well-being score & 17.83 & 3.54 \\
\hline & TFEQ-18 score & 42.58 & 7.13 \\
\hline & TFEQ-18 cognitive restraint subscale & 14.75 & 4.18 \\
\hline
\end{tabular}

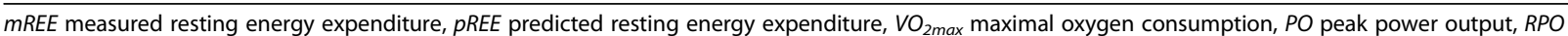
relative power output, $A T$ anaerobic threshold, $R C$ respiratory compensation point, $[\mathrm{La}]_{\text {max }}$ lactate concentration at the end of the test, $[\mathrm{La}]_{5 \mathrm{~min}}$ lactate concentration $5 \mathrm{~min}$ after the end of the test, TFEQ the three factor eating questionnaire

Our results indicate that this was a sample of well-trained healthy endurance athletes. Average training time was $2 \mathrm{~h}$ and $4 \mathrm{~min}(80.6 \%$ spent cycling, $9.3 \%$ running and $10.1 \%$ swimming). Furthermore, mean $\mathrm{VO}_{2 \max }$ showed that $25 \%$ of participants are at the performance level $3\left(\mathrm{VO}_{2 \max }\right.$ between 55.0 and $64.9 \mathrm{ml} / \mathrm{min} / \mathrm{kg}$ ), $33.3 \%$ at the performance level $4\left(\mathrm{VO}_{2 \max }\right.$ between 65 and $\left.71 \mathrm{ml} / \mathrm{min} / \mathrm{kg}\right)$ and $41.6 \%$ are professional athletes with performance level 5 $\left(\mathrm{VO}_{2 \max }>71 \mathrm{ml} / \mathrm{min} / \mathrm{kg}\right)$ (Fig. 3). In addition to endurance performance, we report good jumping capacity as well as the agility with motor task execution times within the normal range expected for the sex and age of the participants (mean time 6.49 s). Hormone levels were within the normal range without any pathological findings, with only one participant with testosterone levels in the lower quartile reference range. Serum iron levels were also in the healthy range, and there were no pathological findings in the complete blood count (not presented in Table 2). 
Our main findings are related to energy and metabolic parameters in this healthy, well-trained sample of endurance athletes. EI was $3078 \mathrm{kcal}$ and EEE was $1173 \mathrm{kcal}$. Calculated energy availability was $29.5 \mathrm{kcal}$ kg FFM $(95 \%$ CI 25.6 to 33.4).

Pearson correlation analysis did not show any significant correlations between anthropometric parameters, performance parameters, hormone levels, or any other blood parameter and EA. However, we found that EA has significant negative correlation with $\operatorname{EEE~}(r=-.618$, $p=.016)$ and that EI had significant positive correlation with cognitive restraint subscale of TFEQ $(r=.559$, $p=.03)$, while it was negatively correlated with mREE $(r=-.578, p=.025)$ and mREE/pREE ratio $(r=-.549$, $p=.032)$. Nine $(n=9 ; 75 \%)$ participants reported critical cognitive restraint, which is any value $\geq 13$ indicating possible LEA presence.

A t-test for independent samples was used to compare subgroups of subjects with EA $\geq 30 \mathrm{kcal} / \mathrm{kg}$ FFM/day $(n=6)$ and subjects with EA $<30 \mathrm{kcal} / \mathrm{kg} \mathrm{FFM} /$ day $(n=$ 6). There were no significant differences in any of the compared parameters.

\section{Discussion}

This study design was set to measure actual EA in healthy endurance athletes in the pre-race period. The mean EA measured in this study supports the theory that the threshold for LEA in male endurance athletes might be below the threshold set for females. In addition, we confirmed cognitive restraint could be useful for early detection of energy conservation. The high cognitive restraint as measured in our sample stresses the need of eating behavior screening in endurance athletes in order to reduce the risk of disordered eating patterns and eating disorders.

\section{Energy markers}

As expected, anthropometric measurements showed the subjects were lean (body fat $M=10.2 \% \pm 2.5 \%$ ). They trained more than $2 \mathrm{~h}$ per day, expending $1173 \mathrm{kcal}$ on daily average. According to physiological parameters obtained at the incremental test, subjects were trained $(n=$ $3)$, well-trained $(n=4)$ and professional athletes $(n=5)$ [13]. Their mean EA was low - it was $29.5 \mathrm{kcal} / \mathrm{kg}$ FFM/ day and according to Melin et al. [22] it would be considered clinically relevant and symptomatic. Two thirds of the subjects $(66.6 \%)$ had EA $<30$, which is in accordance with studies showing prevalence of LEA is high in athletes [3]. However, Fagerberg (2018) has suggested that in male athletes a prolonged EA $<25 \mathrm{kcal} / \mathrm{kg}$ FFM/ day could be the critical value, although this paper was referring to strength and not endurance athletes. Our findings support the Fagerberg proposal, but the true cut-off value of EA will have to be investigated more thoroughly in future studies, so that these predictions are supported by relevant evidence. Greater EEE was associated with lower EA $(r=-618, p=.016)$. This situation raises concern because pre-race season EEE should be coupled with sufficient EI to ensure optimization of adaptation to training.

We also aimed to find any association between energy conservation and EA. In females, LEA and mREE/pREE are associated and this association has been shown primarily on women with amenorrhoea [9, 23-27]. In males, it is not yet clear if EA and energy conservation are indeed connected. Furthermore, it remains an open question whether the cut-off point of $\mathrm{mREE} / \mathrm{pREE}<0.9$ could be used as a potential screening marker for LEA. In our sample, mean mREE/pREE was 1.03 , which was unexpected when considering mean EA was under proposed optimal EA value ( $\geq 40 \mathrm{kcal} / \mathrm{kg} \mathrm{FFM} /$ day) for men [22]. In this study, we suggest there are two possible reasons why we failed to show this association. The first is that while mREE/pREE might indeed be correlated to LEA, we do not know the threshold for LEA in men. From our study we suspect the mean EA values were simply not low enough for the marker mREE/pREE to show energy conservation (i.e. $\mathrm{mREE} / \mathrm{pREE}<0.9$ or even lower [24]). The second reason could be that greater sample size might reveal more since there was only one subject with $\mathrm{mREE} / \mathrm{pREE}<0.9$ in our sample. However, since our participants were healthy athletes without any LEA signs, the likely explanation is that they did not have LEA. Therefore, the mean mREE/pREE was close to 1 , which is an expected value when there is no energy conservation. Although the athletes had a mean $\mathrm{EA}=30$ $\mathrm{kcal} / \mathrm{kg} \mathrm{FFM} /$ day, this suggests that LEA was not present.

\section{Cognitive restraint}

Cognitive restraint means that a person consumes less than they like to and does not tell anything about energy balance [28]. Gibbs et al. [25] showed that cognitive restraint $\geq 13$ might be a useful marker for LEA in exercising women. We were not able to show an association between cognitive restraint $\geq 13$ and lower EA in our sample of male endurance athletes. This might be due to high mean cognitive restraint in our sample. $75 \%$ of our participants had greater values than 13 , which is worrying since this is their eating behavior in the pre-race season preparation period when the pressure on optimal body mass is not yet high. The lowest body mass should be achieved in the competitive season. Secondly, subjects with greater EI had higher cognitive restraint $(r=.599$, $p=.03$ ). Expressing high cognitive restraint could lead to disordered eating. It is known that when entering prerace season preparation period, endurance athletes have high energy demands due to high training volume. This 
should be coupled with satisfactory EI in order to achieve good training adaptation and recovery. High cognitive restraint in our sample suggests athletes might intentionally restrict their EI in order to achieve optimal body composition. Finally, the bigger cognitive restraint, the lower were mREE and $\mathrm{mREE} / \mathrm{pREE}(r=-.578, p=$ .025 and $r=-.549, p=.032$, respectively). cognitive restraint could thus be associated with energy conservation as measured by mREE and expressed by mREE/pREE.

\section{Performance}

There were no correlations between any performance variables and EA or energy conservation. We suspect that a larger sample size might reveal more. Since it is very difficult to find athletes who meet all the inclusion criteria and are willing to undergo all the procedures of an objective EA measurement, reducing EA in the same individuals might be an easier way to see if performance is related to EA or energy conservation. This could also be useful to see if different performance modalities respond differently to EA changes.

\section{What is the threshold for LEA?}

In order to detect a possible threshold, we divided subjects into two groups separated by EA $=30 \mathrm{kcal} / \mathrm{kg}$ FFM/ day. We failed to find any differences in endurance, strength, agility performance or blood parameters. In addition, there were no differences in testosterone's functional health effects (morning erections). This indicates that $\mathrm{EA}=30 \mathrm{kcal} / \mathrm{kg} \mathrm{FFM} /$ day might not be the actual threshold for LEA in men as proposed before by Viner et al. [19]. A lower threshold might be more accurate. Unfortunately, dividing subjects based on a threshold of $15 \mathrm{kcal} / \mathrm{kg}$ FFM/day as suggested by Koehler et al. [29] was not possible for analysis since only one of the subjects reached EA $<15 \mathrm{kcal} / \mathrm{kg} \mathrm{FFM} /$ day. The possibility that the threshold in men could be lower is also supported by blood test results. All measured parameters (full blood count, ferritin, serum Fe, T3, TSH, morning testosterone, fasting insulin, IGF-1, 9 am cortisol) were normal in all participants, despite mean EA was lower than $30 \mathrm{kcal} / \mathrm{kg} \mathrm{FFM} /$ day. LEA must persist over a long period of time to produce health or performance changes, and it is not possible to draw definitive conclusions from a single EA objective measurement. In further research, such measurements should be repeated more often in the same participants to see if their mean EA is indeed lower than $30 \mathrm{kcal} / \mathrm{kg} \mathrm{FFM} /$ day. Also, future research should focus on inducing lower EA in the same participants. This could also be the next step in order to find if a lower threshold indeed shows differences in hormones and/or performance.

\section{Limitatons}

We would like to acknowledge that a more homogenous sample of only one endurance discipline would be more optimal. As known in this research area, finding participants that are willing to accept the high burden of EA measurement is challenging. Still, this is one of the largest sample sizes of trained endurance athletes when measured with objective EA methodology. This is why we believe this paper is an important contribution to current knowledge. In addition, other individual characteristics of athletes influence performance. A study comparing different EA in same individuals would be a more appropriate way to compare performance.

\section{Conclusions}

This paper suggests that psychological evaluation such as cognitive restraint in the TFEQ might be more appropriate where there are no signs of RED-S for assessing energy conservation and possible suboptimal EA. This study adds to our knowledge that the threshold for LEA in men is indeed probably lower than $30 \mathrm{kcal} / \mathrm{kg}$ FFM/ day. Further studies with objective measurement of EA in athletes with apparent LEA or laboratory induced LEA should be performed to determine the threshold for LEA or refute its existence. Practical application of this study is that coaches and their athletes might benefit from cognitive restraint assessment in order to prevent energy conservation.

\section{Abbreviations \\ $[\mathrm{La}]_{5 \mathrm{~min}}$ : Lactate concentration 5 minutes after the end of the test; \\ $[\mathrm{La}]_{\max }$ : Lactate concentration at the end of the test; AT: Anaerobic threshold; CMJ: Countermovement jump; CR: Cognitive restraint; EA: Energy availability; EEE: Exercise energy expenditure; El: Energy intake; Fe: Serum iron; FFM: Fat- free mass; IGF-1: Insulin like growth factor 1; LEA: Low Energy Availability; mREE: measured resting energy expenditure; PO: Peak power output; pREE: predicted resting energy expenditure; RC: Respiratory compensation point; RED-S: Relative Energy Deficiency in Sport syndrome; RPO: Relative power output; T3: Triiodothyronine; TFEQ-R18: Three Factor Eating \\ Questionnaire; TSH: Thyroid stimulating hormone; $\mathrm{VO}_{2 \text { max }}$ : Maximal oxygen uptake}

\section{Supplementary Information}

The online version contains supplementary material available at https://doi. org/10.1186/s12970-021-00419-3.

\section{Additional file 1.}

Additional file 2.

\section{Acknowledgements}

This work was supported by the Slovenian Research Agency [P5-0147].

\section{Authors' contributions}

IJ planned, supervised, conducted the study, reported all the work, prepared and edited the manuscript. NK planned the study and edited the manuscript. VH prepared and edited the manuscript. DS conducted the study, reported part of the work and prepared the manuscript. SR planned, conducted the study, prepared and edited the final manuscript. The authors read and approved the final manuscript. 


\section{Funding}

The study was funded by the Slovenian Research Agency (research grant: P5-0147). The funder had no role in study design, data collection and analysis, decision to publish, or preparation of the manuscript.

Availability of data and materials

Data are available upon reasonable request.

\section{Declarations}

\section{Ethics approval and consent to participate}

National medical ethical approval was acquired before the start of the study (No. 0120-202/2020/5). All participants signed a written consent for their data to be analyzed and published anonymously.

\section{Consent for publication}

Not applicable.

\section{Competing interests}

The authors declare that they have no competing interests.

\section{Author details}

${ }^{1}$ Faculty of Sport, University of Ljubljana, Gortanova 22, 1000 Ljubljana, Slovenia. ${ }^{2}$ Department of Sport and Exercise Sciences, Durham University, Durham, UK.

Received: 25 November 2020 Accepted: 3 March 2021

Published online: 18 March 2021

\section{References}

1. Burke LM, Close GL, Lundy B, Mooses M, Morton JP, Tenforde AS. Relative energy deficiency in sport in male athletes: a commentary on its presentation among selected groups of male athletes. Int J Sport Nutr Exerc Metab. 2018;28(4):364-74 [cited 2018 Oct 15]. Available from: http://www. ncbi.nlm.nih.gov/pubmed/30040508.

2. Mountjoy M, Sundgot-Borgen J, Burke L, Carter S, Constantini N, Lebrun C, et al. The IOC consensus statement: beyond the female athlete triad_relative energy deficiency in Sport (RED-S). Br J Sports Med 2014; 48(7):491-497. Available from: https://doi.org/10.1136/bjsports-2014-093502

3. Ackerman KE, Holtzman B, Cooper KM, Flynn EF, Bruinvels G, Tenforde AS, et al. Low energy availability surrogates correlate with health and performance consequences of Relative Energy Deficiency in Sport. Br J Sports Med. 2018;53(10):628-33 [cited 2018 Oct 2]. Available from: http:// www.ncbi.nlm.nih.gov/pubmed/29860237.

4. Loucks $A B$, Thuma JR. Luteinizing hormone pulsatility is disrupted at a threshold of energy availability in regularly menstruating women. J Clin Endocrinol Metab. 2003:88(1):297-311.

5. Mountjoy M, Sundgot-Borgen J, Burke L, Ackerman KE, Blauwet C, Constantini N, et al. International olympic committee (ioc) consensus statement on relative energy deficiency in sport (RED-S): 2018 update. Int J Sport Nutr Exerc Metab 2018;28(4):316-331. [cited 2018 Oct 15]. Available from: https://doi.org/10.1123/ijsnem.2018-0136

6. Laughlin GA, Yen SS. Hypoleptinemia in Women Athletes: Absence of a Diurnal Rhythm with Amenorrhea. J Clin Endocrinol Metab 1997;82(1):318321. [cited 2021 Jan 17]. Available from: https://doi.org/10.1210/jcem.82.1.3 840

7. Wasserfurth P, Palmowski J, Hahn A, Krüger K. Reasons for and consequences of low energy Availability in female and male athletes: social environment, adaptations, and prevention. Sport Med Open. 2020;6(1):44.

8. Gibbs JC, Williams NI, Mallinson RJ, Reed JL, Rickard AD, De Souza MJ. Effect of high dietary restraint on energy availability and menstrual status. Med Sci Sports Exerc. 2013:45(9):1790-7.

9. De Souza MJ, West SL, Jamal SA, Hawker GA, Gundberg CM, Williams NI. The presence of both an energy deficiency and estrogen deficiency exacerbate alterations of bone metabolism in exercising women. Bone. 2008;43(1):140-8.

10. Jurov I, Hadžić V, Rauter S. Markers of energy metabolism affect lactate metabolism and aerobic performance in competitive female cyclists. Appl Sci. 2020;10(21):7563 [cited 2020 Oct 27]. Available from: www.mdpi.com/ journal/applsci.
11. Heikura IA, Stellingwerff T, Bergland D, Mero AA, Burke LM. Low energy Availability is difficult to assess but outcomes have large impact on bone injury rates in elite distance athletes. Int J Sport Nutr Exerc Metab. 2018; 28(4):403-11.

12. Capling L, Beck K, Gifford J, Slater G, Flood V, O'Connor H, et al. Validity of dietary assessment in athletes: a systematic review. Nutrients. 2017;9(12): 1313 [cited 2018 Oct 15]. Available from: http://www.mdpi.com/2072-6643/ 9/12/1313.

13. De Pauw K, Roelands B, Cheung SS, de Geus B, Rietjens G, Meeusen R. Guidelines to classify subject groups in sport-science research. Int J Sports Physiol Perform. 2013;8(2):111-22 [cited 2018 Nov 6]. Available from: http:// www.ncbi.n/m.nih.gov/pubmed/23428482.

14. de Weir JB. New methods for calculating metabolic rate with special reference to protein metabolism. J Physiol. 1949;109(1-2):1-9 [cited 2019 Jun 21]. Available from: http://www.ncbi.nlm.nih.gov/pubmed/15394301.

15. Torstveit MK, Fahrenholtz IL, Lichtenstein MB, Stenqvist TB, Melin AK. Exercise dependence, eating disorder symptoms and biomarkers of Relative Energy Deficiency in Sports (RED-S) among male endurance athletes. BMJ Open Sport Exerc Med. 2019;5(1):e000439 [cited 2019 Mar 5]. Available from: http://www.ncbi.nlm.nih.gov/pubmed/30792881.

16. Westerterp KR. Measurement of Energy Expenditure. In: Translational research methods for diabetes, obesity and cardiometabolic drug development. London: Springer London; 2015:169-187. [cited 2019 June 10]. Available from: https://doi.org/10.1007/978-1-4471-4920-0_7

17. Compher C, Frankenfield D, Keim N, Roth-Yousey L. Evidence analysis working group. best practice methods to apply to measurement of resting metabolic rate in adults: a systematic review. J Am Diet Assoc. 2006;106(6): 881-903 [cited 2019 Jun 21]. Available from: http://www.ncbi.n/m.nih.gov/ pubmed/16720129.

18. Harris JA, Benedict FG. A biometric study of human basal metabolism. Proc Natl Acad Sci 1918;4(12):370-373. Available from: https://doi.org/10.1073/ pnas.4.12.370

19. Viner RT, Harris M, Berning JR, Meyer NL. Energy availability and dietary patterns of adult male and female competitive cyclists with lower than expected bone mineral density. Int J Sport Nutr Exerc Metab. 2015;25(6): 594-602.

20. Jurov I, Kajtna T, Milić R, Rauter S. Recovery and dietary factors as predictors of physiological parameters in cyclists. Med Dello Sport. 2020;73(02):220-30.

21. McLean BD, Coutts AJ, Kelly V, McGuigan MR, Cormack SJ. Neuromuscular, endocrine, and perceptual fatigue responses during different length between-match microcycles in professional rugby league players. Int J Sports Physiol Perform. 2010;5(3):367-83.

22. Melin AK, Heikura IA, Tenforde A, Mountjoy M. Energy Availability in Athletics: Health, Performance, and Physique. Int J Sport Nutr Exerc Metab. 2019:29(2):152-64 [cited 2019 Jun 7]. Available from: http://www.ncbi.nlm. nih.gov/pubmed/30632422.

23. De Souza MJ, Hontscharuk R, Olmsted M, Kerr G, Williams NI. Drive for thinness score is a proxy indicator of energy deficiency in exercising women. Appetite. 2007:48(3):359-67 cited 2018 Nov 12]. Available from: http://www.ncbi.nlm.nih.gov/pubmed/17184880.

24. De Souza MJ, Lee DK, VanHeest JL, Scheid JL, West SL, Williams NI. Severity of energy-related menstrual disturbances increases in proportion to indices of energy conservation in exercising women. Fertil Steril. 2007:88(4):971-5 [cited 2018 Nov 12]. Available from: http://www.ncbi.n/m.nih.gov/pubmed/1 7418159 .

25. Gibbs JC, Williams NI, Scheid JL, Toombs RJ, De Souza MJ. The association of a high drive for thinness with energy deficiency and severe menstrual disturbances: confirmation in a large population of exercising women. Int J Sport Nutr Exerc Metab. 2011;21(4):280-90 [cited 2018 Nov 12]. Available from: http://www.ncbi.nlm.nih.gov/pubmed/21813911.

26. Reed JL, De Souza M, Mallinson RJ, Scheid JL, Williams NI. Energy availability discriminates clinical menstrual status in exercising women. J Int Soc Sports Nutr. 2015;12(1):11 Available from: http://www.jissn.com/ content/12/1/11.

27. Scheid JL, De Souza MJ, Hill BR, Leidy HJ, Williams NI. Decreased luteinizing hormone pulse frequency is associated with elevated 24-hour ghrelin after calorie restriction and exercise in premenopausal women. Am J Physiol Endocrinol Metab. 2013;304(1):E109-16 [cited 2018 Nov 12]. Available from: http://www.ncbi.nlm.nih.gov/pubmed/23115078.

28. Stice E, Sysko R, Roberto CA, Allison S. Are dietary restraint scales valid measures of dietary restriction? Additional objective behavioral and 
biological data suggest not. Appetite. 2010;54(2):331-9 [cited 2020 Oct 28]. Available from: /pmc/articles/PMC2830309/?report=abstract.

29. Koehler K, Hoerner NR, Gibbs JC, Zinner C, Braun H, De Souza MJ, et al. Low energy availability in exercising men is associated with reduced leptin and insulin but not with changes in other metabolic hormones. J Sports Sci. 2016;34(20):1921-9.

\section{Publisher's Note}

Springer Nature remains neutral with regard to jurisdictional claims in published maps and institutional affiliations.

Ready to submit your research? Choose BMC and benefit from:

- fast, convenient online submission

- thorough peer review by experienced researchers in your field

- rapid publication on acceptance

- support for research data, including large and complex data types

- gold Open Access which fosters wider collaboration and increased citations

- maximum visibility for your research: over $100 \mathrm{M}$ website views per year

At BMC, research is always in progress.

Learn more biomedcentral.com/submissions 